\title{
ANÁLISE MORFOMÉTRICA DA SUB-BACIA DO CÓRREGO HORIZONTE, ALEGRE-ES, UTILIZANDO O SISTEMA DE INFORMAÇÃO GEOGRÁFICA (SIG)
}

\author{
BERTOSSI, Ana Paula Almeida ${ }^{1}$ \\ KLIPPEL, Valéria Hollunder ${ }^{1}$ \\ PELUZIO, Telma Machado de Oliveira ${ }^{1}$ \\ MENEZES, João Paulo Cunha de ${ }^{1}$ \\ CECÍLIO, Roberto Avelino ${ }^{2}$
}

\begin{abstract}
RESUMO: O objetivo do presente trabalho foi realizar a caracterização morfométrica da sub-bacia do córrego Horizonte, Alegre, ES, a partir da estimativa de alguns parâmetros físicos. Inicialmente foi gerado o Modelo Digital de Elevação (MDE) a partir de cartas topográficas do IBGE, obtidas no banco de dados do GEOBASESES, na escala 1:50.000, utilizando o sistema de informações geográficas, através do software ArcGis 10®. A área de drenagem encontrada foi de $12,77 \mathrm{~km}^{2}$ e o perímetro, de $20,23 \mathrm{~km}$. A sub-bacia hidrográfica do córrego Horizonte tem formato alongado e baixa tendência à ocorrência de enchentes, devido ao coeficiente de compacidade de 1,585, fator de forma de 0,665 e índice de circularidade de 0,39 , razão de elongação de 2,42 , apresentando classificação de ordem 4 segundo Strahler. A densidade de drenagem obtida para a bacia foi de $2,30 \mathrm{~km} / \mathrm{km}^{2}$, indicando boa drenagem do fluxo do córrego, densidade hidrográfica 3,37 rios/ $\mathrm{km}^{2}$ e extensão média de escoamento superficial de $83 \mathrm{~m}$.
\end{abstract}

Palavras-chave: Morfometria. SIG. Manejo de bacias.

SUMMARY: The objective of the work was to perform the morphometric characterization of the subwatershed of the Horizonte stream in Alegre, ES, from the estimation of some physical parameters. Initially, the Digital Elevation Model (DEM) was generated from the topographic maps of IBGE, obtained in the database GEOBASES-ES, in the scale 1:50,000, using the geographic information system through the software ArcGis $10 \AA$. The drainage area found was $2.77 \mathrm{~km}^{2}$ and the perimeter was $20.23 \mathrm{~km}$. The hydrographic sub-watershed of the Horizonte stream has an elongated format and low tendency to occurrence of floods due to the compactness coefficient of 1.585 , shape factor of 0.665 and a circularity index of 0.39 , an elongation ratio of 2.42, showing classification of fourth order according to Strahler. The drainage density obtained for the watershed was $2.30 \mathrm{~km} / \mathrm{km}^{2}$, indicating good drainage of the stream flow, the hydrographic watershed density 3.37 river/ $\mathrm{km}^{2}$ and average length of $83 \mathrm{~m}$ from the surface runoff.

Keywords: Morphometry. GIS. Management of watershed.

\section{INTRODUÇÃO}

As crescentes pressões sobre o planeta terra, para produção de alimentos, fibras e forragem, além da expansão industrial e consequente necessidade de infra-estruturas, devido ao crescimento da população tem dado origem a disputas conflitantes sobre o uso do solo e da

\footnotetext{
${ }^{1}$ Mestrandos da Universidade Federal do Espírito Santo - UFES, e-mail: anapaulabertossi@yahoo.com.br valeria.h.klippel@hotmail.com, tmpeluzio@hotmail.com, jpaulo_bio@hotmail.com

${ }^{2}$ Professor Adjunto, Departamento de Engenharia Florestal, UFES,e-mail: racecilio@ yahoo.com.br
} 
água. Assim, o conhecimento da relação solo-superfície é imprescindível para o monitoramento e planejamento conservacionista do meio.

Neste contexto, a bacia hidrográfica torna-se área ideal para o planejamento integrado no manejo dos recursos naturais, pois é considerada como principal unidade fisiográfica do terreno associada ao fluxo superficial da água (CHRISTOFOLETTI, 1978; GERRA; CUNHA, 1996).

Uma das ferramentas mais importantes na análise hídrica é o levantamento morfométrico de uma bacia, que consiste na caracterização de parâmetros físicos da bacia. Essa caracterização tem grande aplicação como indicadores para previsão do grau de vulnerabilidade da bacia a fenômenos como enchentes, inundações e erodibilidade, dentre outros (CARDOSO et al., 2006; ANDRADE et al., 2008; ANGILLIERI, 2008; GEBREHIWOT, et al., 2011).

Andrade et al. (2008), ao caracterizar a bacia do rio Manso concluiu que os dados morfométricos, juntamente com as informações geradas no SIG, como localização da bacia, área e o Modelo Digital de Elevação (MDE), são instrumentos valiosos para a gestão de recursos hídricos.

A caracterização morfométrica de bacias hidrográficas tem sido feita atualmente com a integração de informações de relevo em ambiente de Sistemas de Informações Geográficas (SIG), procedimento este, que pode ser realizado de modo automático (CARDOSO et al., 2006). De acordo com Tribe (1992) a derivação automática da bacia hidrográfica a partir de um Modelo Digital de Elevação (MDE) é rápida e menos subjetiva, pois oferece maior quantidade de informações que as técnicas manuais aplicadas aos mapas analógicos. Esses modelos são obtidos, hoje, por meio da interpolação de curvas de nível extraídas de uma carta topográfica ou através de imagens de sensores remotos (OLIVEIRA et al., 2010).

O objetivo deste estudo foi realizar a caracterização morfométrica da sub-bacia hidrográfica do córrego Horizonte, a partir da estimativa de alguns parâmetros físicos, procurando destacar e quantificar as formas de relevo e os padrões de drenagem existentes e à propensão de ocorrência de cheias na bacia.

\section{MATERIAL E MÉTODOS}

Área em estudo - A área em estudo consistiu na Bacia Hidrográfica do Córrego Horizonte, localizada sob coordenadas geográficas $41^{\circ} 32^{\prime}$ e $41^{\circ} 38^{\prime}$ de longitude Oeste e $20^{\circ} 43^{\prime}$ e $20^{\circ} 51^{\prime}$ de latitude Sul, com área aproximada de 1.265,36 ha, localizada na Área Experimental do Instituto Federal do Espírito Santo (IFES), em Alegre-ES, às margens da Rodovia BR - 482, 
que liga Alegre a Cachoeiro de Itapemirim (Figura 1). Segundo a classificação de Köppen, o clima da região é do tipo Cwa, caracterizado pelo inverno seco e verão chuvoso.

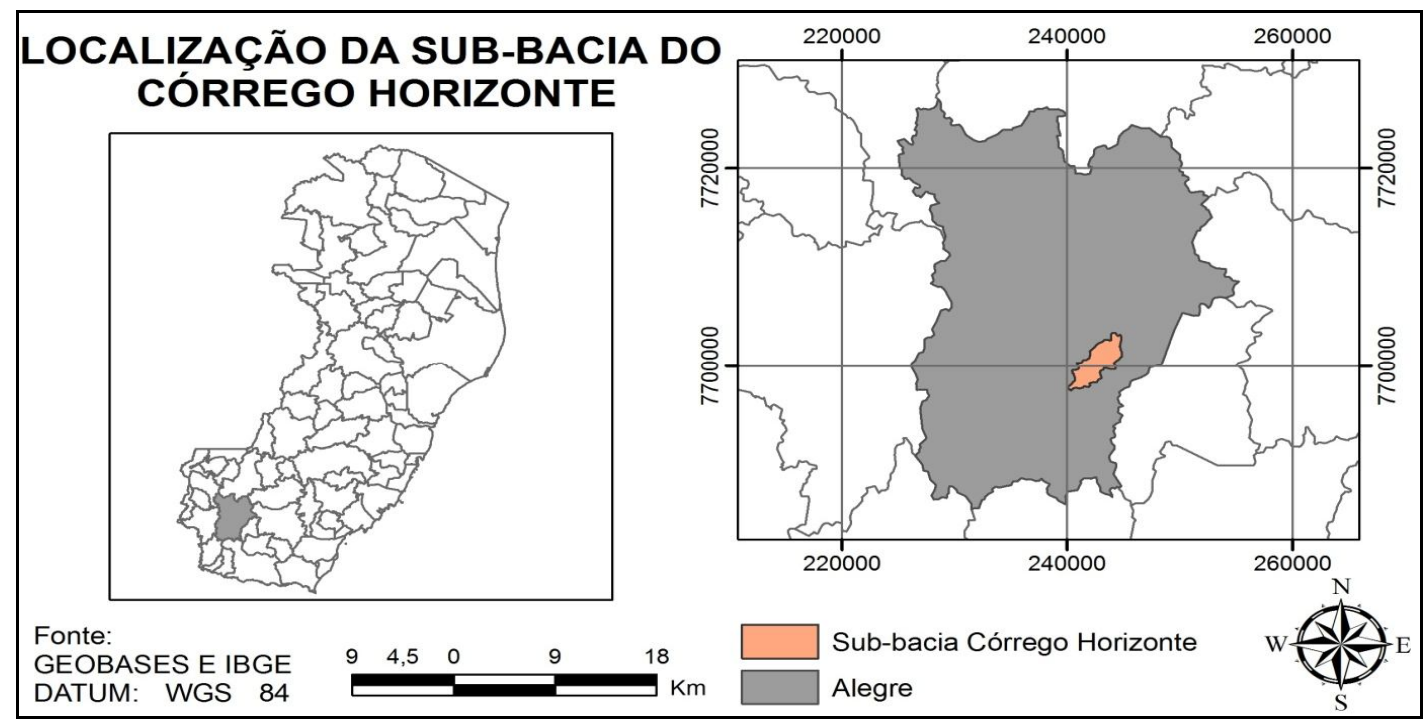

Figura 1- Localização da sub-bacia do córrego Horizonte.

Análise morfométrica - A base de dados e as análises foram geradas através do sistema de informações geográficas, utilizando-se os software ArcGIS 10®, módulo ArcMap e ArcInfo Workstation a partir da base de dados do IBGE na escala 1:50.000, com curvas de nível de 20 em 20 m, através do banco de dados do GEOBASES-ES e Datum WGS84.

Os parâmetros morfométricos foram divididos em três categorias: parâmetros básicos, parâmetros derivados e os parâmetros de forma. Os dados da primeira categoria incluem: área de drenagem (A), perímetro (P), comprimento do curso d'água principal (L), ordem dos cursos de água segundo Strahler (1964), declividade média da bacia (Dm), altitude média da bacia, curva hipsométrica, extensão média do escoamento superficial. Os da segunda categoria são: densidade de drenagem (Dd), densidade de confluência (Dc), densidade hidrográfica ( $\mathrm{Dh})$; e os parâmetros de forma: coeficiente de compacidade (Kc), fator de forma (Kf), índice de circularidade (Ic) e razão de elongação (Re), obtidos a partir das seguintes equações: 


\begin{tabular}{lll}
\hline Densidade de drenagem & $\mathrm{D}_{\mathrm{d}}=\mathrm{L}_{\mathrm{tot}} / \mathrm{A}$ & HORTON, 1945 \\
Densidade de Confluência & $\mathrm{D}_{\mathrm{c}}=\mathrm{NC} / \mathrm{A}$ & TUCCI, 1997 \\
$\begin{array}{l}\text { Densidade Hidrográfica } \\
\text { Coeficiente de compacidade }\end{array}$ & $\mathrm{D}_{\mathrm{h}}=\mathrm{N} / \mathrm{A}$ & CHRISTOFOLETTI, 1974 \\
& $\mathrm{K}_{\mathrm{c}}=0,28\left(\frac{P}{\sqrt{A}}\right)$ & VILLELA MATTOS 1975 \\
Fator de forma & $\mathrm{K}_{\mathrm{f}}=\mathrm{A} / \mathrm{L}_{\mathrm{ax}}^{2}$ & \\
$\begin{array}{l}\text { Índice de circularidade } \\
\text { Razão de elongação }\end{array}$ & $\mathrm{IC}=12,57\left(\mathrm{~A} / \mathrm{P}^{2}\right)$ & HORTON, 1932 \\
& $\mathrm{R}_{\mathrm{e}}=1,128(\sqrt{(A / L))}$ & $\underline{\text { SCHUMM, 1956 }}$ \\
\hline
\end{tabular}

\section{RESULTADOS E DISCUSSÃO}

O resumo das características físicas calculadas para a sub-bacia do Córrego Horizonte, Alegre/ES está apresentado na tabela 1.

Tabela 1 - Características físicas da sub-bacia hidrográfica do Córrego Horizonte, Alegre, ES.

\begin{tabular}{ll}
\hline Características físicas & Resultados \\
\hline Área de drenagem (A) & $12,77 \mathrm{Km}^{2}$ \\
Perímetro (P) & $20,23 \mathrm{Km}$ \\
Coeficiente de compacidade (Kc) & 1,585 \\
Fator de forma (Kf) & 0,3285 \\
Índice de circularidade (IC) & 0,39 \\
Razão de elongação(Re) & 2,42 \\
Comprimento do curso d'água principal(L) & $4,38 \mathrm{~km}$ \\
Densidade de drenagem (Dd) & $2,30 \mathrm{~km} / \mathrm{km}^{2}$ \\
Densidade hidrográfica (Dh) & $2,37 \mathrm{rios} / \mathrm{Km}^{2}$ \\
Declividade média da bacia (Dm) & $41 \%$ \\
Extensão média do escoamento superficial (l) & $83 \mathrm{~m}$ \\
Altitude máxima (m) & $660 \mathrm{~m}$ \\
Altitude média (m) & $297 \mathrm{~m}$ \\
Altitude mínima & $120 \mathrm{~m}$ \\
Ordem da bacia & 04 \\
\hline
\end{tabular}

De acordo com os resultados morfométricos, pode-se sugerir que a sub-bacia hidrográfica do Córrego do Horizonte mostra-se pouco suscetível a enchentes em condições normais de precipitação, ou seja, excluindo-se eventos de intensidades anormais, pelo fato de o coeficiente de compacidade apresentar o valor afastado da unidade $(1,585)$ e seu fator de 
forma exibir um valor baixo $(0,3285)$, não podendo afirmar devido à falta de dados de uso e ocupação da terra, tipo de vegetação e solo, dentre outras características.

Esses valores indicam que a sub-bacia apresenta uma tendência à forma alongada. Tal fato pode ainda ser comprovado pelo índice de circularidade, possuindo um valor de $(0,39)$ onde valores menores que 0,51 sugerem que a bacia tende a ser mais alongada, favorecendo o processo de escoamento (MILLER, 1953; SCHUMM, 1956). Em bacias com forma alongadas, há menores possibilidades de enchentes, diferente do que ocorre em bacia de forma circular, onde as chuvas ocorrerem simultaneamente em toda a sua extensão, concentrando todo volume de água no tributário principal (CARDOSO et al., 2006).

A densidade de drenagem foi considerada baixa, pois o valor encontrado foi menor que $5 \mathrm{~km} \mathrm{~km}^{-2}$ segundo a classificação de Christofoletti (1974), indicando que esta bacia hidrográfica apresenta baixa relação entre o comprimento de rios e a área da bacia indicando um eficiente escoamento de fluxo de água e boa infiltração para o lençol freático, ou seja uma menor propensão a inundações.

Em relação à declividade a sub-bacia do córrego Horizonte apresenta relevos que variam de plano a fortemente montanhoso, havendo predominância do relevo montanhoso (Figura 2). Conforme a Tabela 2, aproximadamente $28 \%$ da área da microbacia se enquadra na inclinação de $>75 \%$.

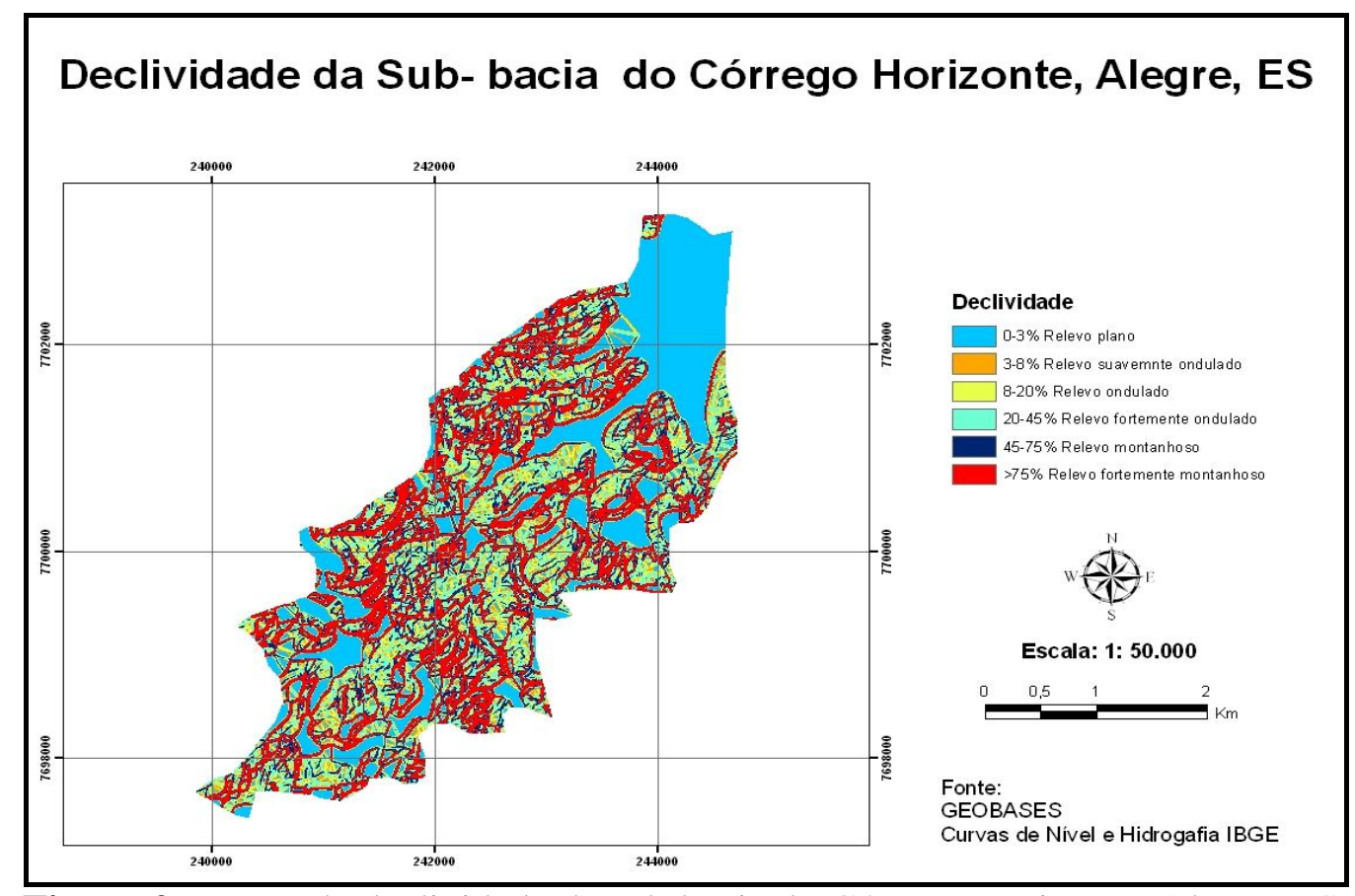

Figura 2 - Mapa de declividade da sub-bacia do Córrego Horizonte, Alegre, ES. 
Tabela 2. Discriminação da declividade (\%), tipos de relevo e suas respectivas áreas, na subbacia do Córrego Horizonte, Alegre, ES.

\begin{tabular}{lll}
\hline Declividade (\%) & Discriminação & Área (\%) \\
\hline $0-3$ & Relevo plano & 24,00 \\
$3-8$ & Relevo suavemente ondulado & 5,06 \\
$8-20$ & Relevo ondulado & 10,70 \\
$20-45$ & Relevo fortemente ondulado & 18,00 \\
$45-75$ & Relevo montanhoso & 14,67 \\
$>75$ & Relevo fortemente montanhoso & 27,5 \\
\hline Total & & $\mathbf{1 0 0 , 0 0}$ \\
\hline
\end{tabular}

A declividade de uma bacia hidrográfica é relevante no seu planejamento, tanto para com o cumprimento da legislação quanto para garantir a eficiência das intervenções antrópicas no meio; possui ainda importante papel na distribuição da água entre o escoamento superficial e subterrâneo, dentre outros processos. A ausência de cobertura vegetal, classe de solo e intensidade de chuvas, dentre outros, associada à maior declividade, conduzirá à maior velocidade de escoamento, menor quantidade de água armazenada no solo e resultará em enchentes mais pronunciadas, sujeitando a bacia à degradação. Assim, a magnitude dos picos de enchentes ou a menor oportunidade de infiltração e suscetibilidade à erosão dos solos dependem da rapidez com que ocorre o escoamento superficial, que está fortemente relacionado com o relevo (TONELLO, 2006).

A altitude na bacia hidrográfica varia de $120 \mathrm{~m}$ a $660 \mathrm{~m}$, resultando numa amplitude altimétrica de $297 \mathrm{~m}$. A altitude influência as diferenças de temperatura dentro da bacia, além de seus mecanismos de evaporação e da forma com que a precipitação é captada. Outra influência relacionada a altas altitudes é a retenção maior de umidade, com formação de neblinas gerando microclimas. Para melhor distribuição do uso do solo na bacia, é importante que se observem as áreas elevadas e declivosas (Figura 3), para uma melhor adequação da aptidão das terras (SANTOS, 2007). Dessa forma, tal distribuição poderá ser útil para um planejamento ou manejo da microbacia em questão. 


\section{Hipsometria da Sub- bacia do Córrego Horizonte, Alegre, ES}
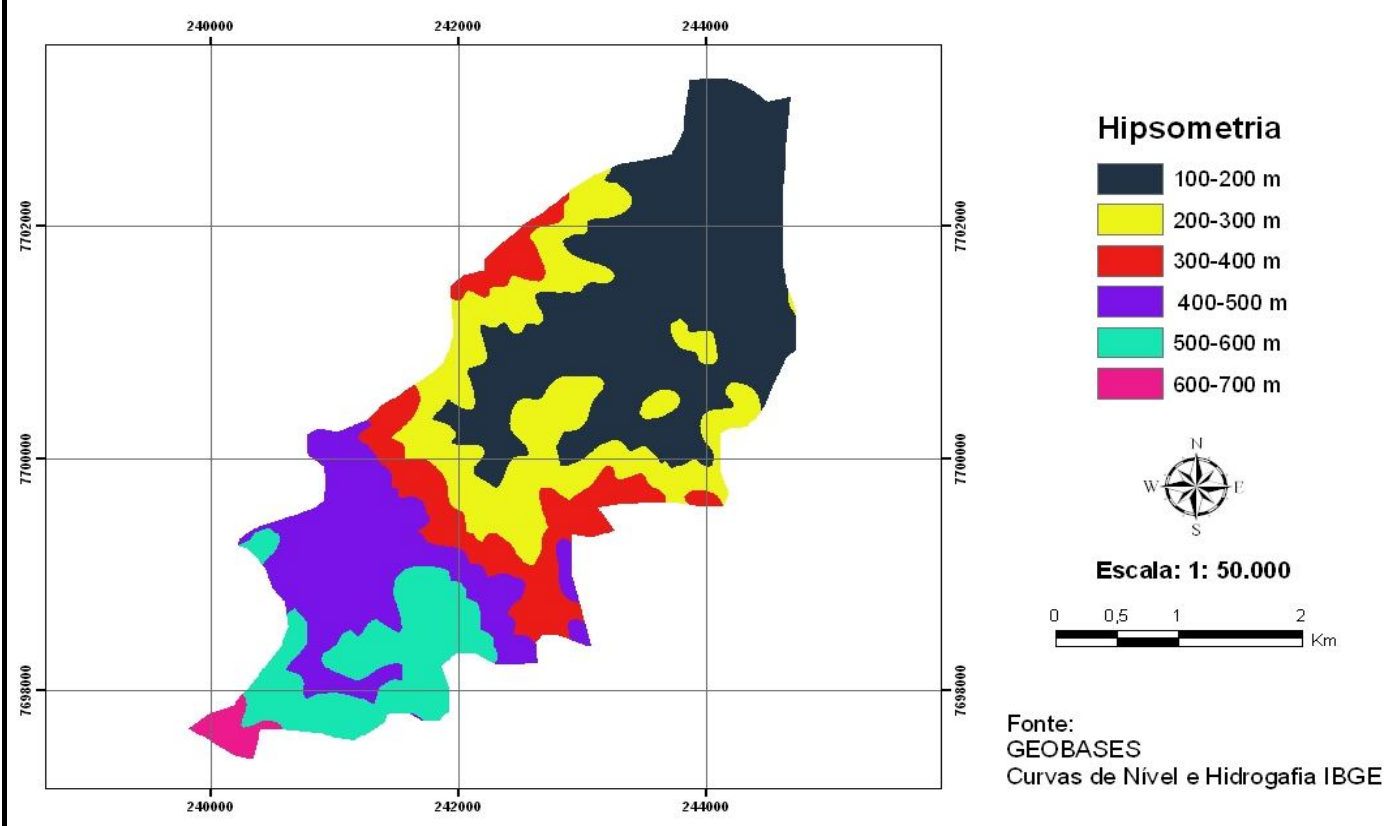

Figura 3 - Mapa de hipsometria da sub-bacia do Córrego Horizonte, Alegre, ES.

De acordo com Tonello et al. (2006), a altitude média influencia a quantidade de radiação que ela recebe e, consequentemente, a temperatura e a precipitação. Quanto maior a altitude da bacia, menor a quantidade de energia solar que o ambiente recebe e, portanto, menos energia estará disponível para esse fenômeno. Além do balanço de energia, a temperatura também varia em função da altitude, grandes variações na altitude ocasionam diferenças significativas na temperatura, que, por sua vez, também causa variações na evapotranspiração.

Em relação ao sistema de drenagem proposta por Strahler (1952) elimina o conceito de que o rio principal deve ter o mesmo número de ordem em toda a extensão e a necessidade de se refazer a numeração a cada confluência. Nesta classificação o córrego Horizonte compreende um canal de $4^{\mathrm{a}}$ ordem (Figura 4$)$. 


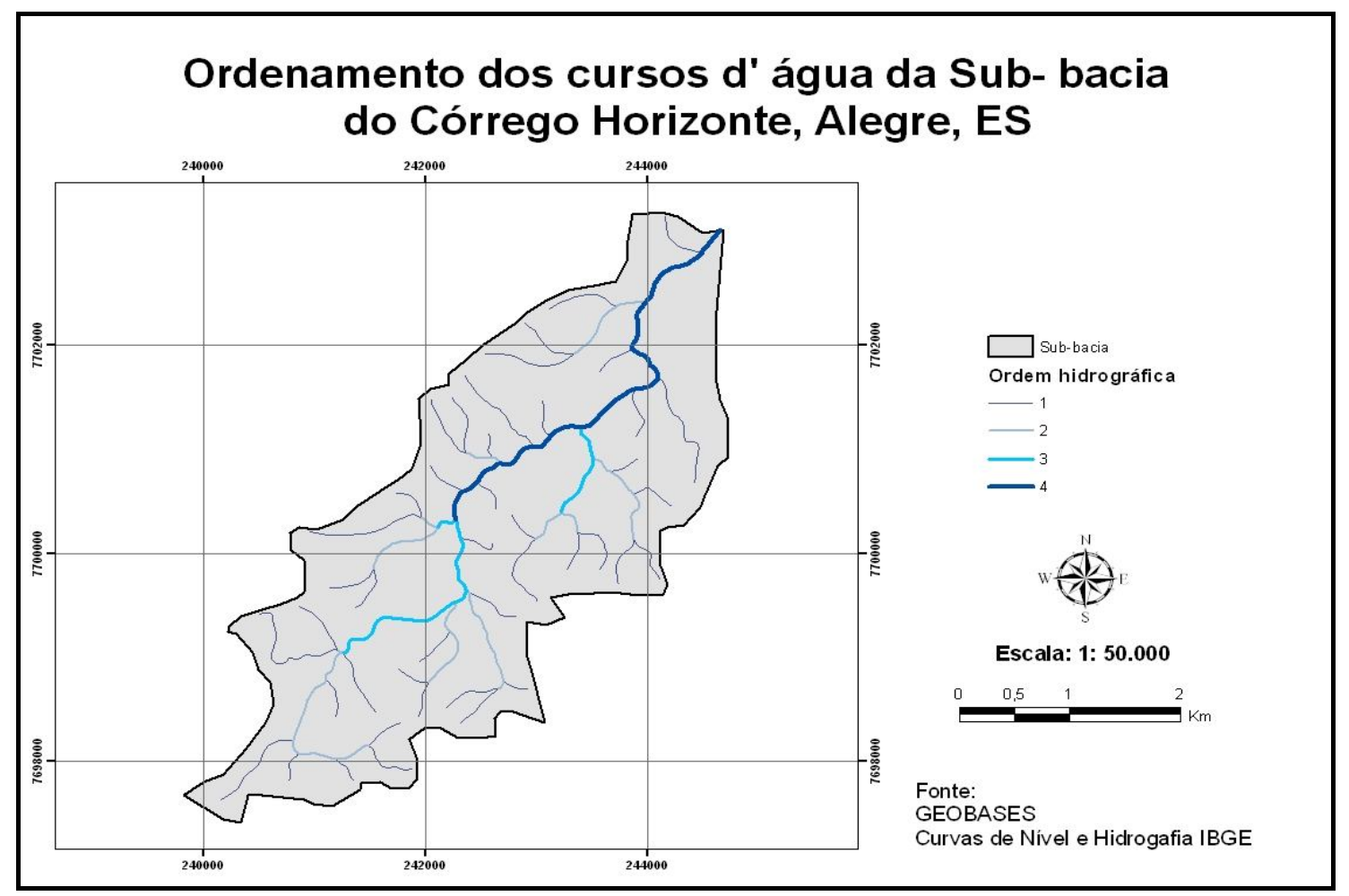

Figura 4 - Mapa de ordenamento dos cursos d'água da sub-bacia do Córrego Horizonte, Alegre, ES.

\section{CONCLUSÃO}

De acordo com os resultados, pode-se concluir que:

- A utilização das ferramentas de análise espacial do software ArcGIS, com base nos dados de altitude contidos no MDE, permitiram a caracterização morfométrica da bacia hidrográfica estudada podendo auxiliar a gestão e o gerenciamento dos recursos hídricos, razão por que se mostra uma alternativa prática e viável ao minimizar custos e tempo na execução dos trabalhos, usando apenas boa qualidade dos dados topográficos.

- A caracterização morfométrica da sub-bacia hidrográfica córrego Horizonte apresentase de forma mais alongada, sendo comprovado pelo índice de circularidade, coeficiente de compacidade e fator de forma, e densidade de drenagem é de 2,30 $\mathrm{km} / \mathrm{km}^{2}$, podendo-se sugerir que a bacia em estudo apresenta um bom sistema de drenagem.

- A sub-bacia hidrográfica do córrego Horizonte é de quarta ordem, pelo método de classificação de Strahler. 
- As características do relevo indicam que a sub-bacia possui declividade média de $41 \%$, com relevo montanhoso e altitude média de $297 \mathrm{~m}$

- O conhecimento quantitativo das características morfométricas da bacia estudada permite traçar melhores estratégias para subsidiarem tomadas de decisões, se transformando num banco de dados primário em estudos mais avançados.

\section{REFERÊNCIAS}

ANDRADE, N.L.R.et al. Caracterização morfométrica e pluviométrica da bacia do rio Manso - MT. Geociências, São Paulo, v.27, n.2, p. 237-248, 2008.

ANGILLIERI, M.Y.E. 2 Morphometric analysis of Colangüi river basin and flash flood hazard, San Juan, Argentina. Environmental Geology, Berlin, v. 55, p. 107 - 111, 2008.

CARDOSO, C.A.et al. Caracterização morfométrica da Bacia Hidrográfica do Rio Debossan, Nova Friburgo, RJ. Revista Árvore, v.30, n.2, p.241-248, 2006.

CHRISTOFOLETTI, A. Geomorfologia. São Paulo: Edgard Blucher, 1974.

CHRISTOFOLETTI, A. Morfologia de bacias de drenagem. Notícia Geomorfológica, Campinas, n.18, p.130-138, 1978.

GEBREHIWOT, S.G.; IISTEDT, U.; GÄRDENAS, A.I., BISHOP, K. Hidrological characterization of watersheds in the Blue Nile Basin, Ethiopia. Hydrology and Earth System Sciences. v.15, p. 11-20, 2011.

GERRA, A.J.T.; CUNHA, S.B. Degradação ambiental. In: CUNHA, S.B. Geomorfologia e meio ambiente. Rio de Janeiro: Bertrand Brasil. p. 337-339. 1996.

HORTON, R.E. Drainage basin characteristics. Trans. .Amer.Geophys. Union, v.13, pp.350-361, 1932.

HORTON, R.E. Erosional development of streams and their drainage basins. Hydrophysical approach to quantitative morphology, Geological Society of America Bulletin, n. 56 pp. 275-370, 1945.

IBGE - Instituto Brasileiro de Geografia e Estatística. Carta topográfica: Espera Feliz, Divino de São Lourenço. Escala 1:50.000. 1977.

MILLER, V.C.A. Quantitative Geomorphic Study of Drainage Basin Characteristics in the Clinch Mountain Area. Virginia and Tennessee Technical Report 3, Office of Naval Research, Department of Geology, Columbia University, New York, 1953. 
OLIVEIRA, P.T.S.et al. Caracterização morfométrica de bacias hidrográficas através de dados SRTM. Revista Brasileira de Engenharia Agrícola e Ambiental, Campina Grande, PB, v.14, n.8, p.819-825, 2010.

SANTOS, A.R. ArcGis - Aplicação para Dados espaciais. Fundação de Desenvolvimento Agropecuário do Espírito Santo - FUNDAGRES. Vitória/ES. 2007.

SCHUMM, S.A., Evolution of drainage systems and slopes in badlands at Perth Ambos, New Jersey, Geological Society of America Bulletin 67 (1956), pp. 597-646, 1956.

STRAHLER, A.N. Quantitative geomorphology of drainage basin and channel networks. In: Chow VT (ed) Handbook of applied hydrology. McGraw Hill, New York, pp.4-76, 1964.

TONELLO K.C.et al. Morfometria da bacia Hidrográfica da cachoeira das Pombas, Guanhães - MG. Revista Árvore, Viçosa-MG, n.5, p.849-857, 2006.

TRIBE, A. Automated recognition of valley heads from digital elevation models. Earth Surface Processes \& Landforms, 16:33-49, 1992.

TUCCI, C.E.M. (Org.) Hidrologia: ciência e aplicação. 2.ed. Porto Alegre: Editora da Universidade: ABRH, 1997. (Coleção ABRH de Recursos Hídricos; v.4).

VILLELA, S.M., MATTOS, A. A Hidrologia aplicada. São Paulo: McGraw-Hill do Brasil, p. 245, 1975. 